Z. Epileptol. 2020 33:50-61 https://doi.org/10.1007/s10309-019-00302-x Published online: 7 January 2020

(C) The Author(s) 2019

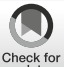

Friedhelm C. Schmitt ${ }^{1,2} \cdot$ H.-Joachim Meencke ${ }^{2}$

' Department of Neurology, University Otto-von-Guericke, Magdeburg, Germany

${ }^{2}$ Epilepsy Center Berlin Brandenburg at Ev. Krankenhaus Königin Elisabeth Herzberge, Teaching Hospital, Humboldt University, Berlin, Germany

\title{
Factors predicting 10-year seizure freedom after temporal lobe resection
}

\section{A monocentric, continuous extra-long-term evaluation}

\section{Introduction}

For patients with pharmacoresistant temporal lobe epilepsy (TLE), resective surgery has become a widely accepted, evidence-based, and advised [9] procedure to obtain seizure freedom. Cure, i.e., seizure freedom without medication, is a major motivation for patients to undergo presurgical evaluation [3, 37]. For a putative beneficial, yet irreversible, surgical procedure, prognostic factors based on long follow-up periods enhance the quality of patient counseling substantially.

The only randomized controlled study by Wiebe [42] has a follow-up period of 1 year. More than a decade later the Early Randomized Surgical Epilepsy Trial [8] added 2-year follow-up data, which supported the beneficial role of resective surgery compared with medical treatment. Yet, the study was prematurely finalized because of its slow recruitment rate. Studies using meta-analyses of several cohort studies [33, 38, 39], retrospective data acquisition in larger cohorts over a long time period $[1,20,23,27$, 40], or statistical modeling methods [4] circumvented this recruitment matter.

In single-center studies, seizure freedom rates for anterior lobe resection vary between $58 \%$ after 1 year in 80 patients [42], to $59 \%$ after 2 years in 70 patients [1] and 55\% after 5 years in 407 patients [40]. The last study is important because of the large patient number and the long follow-up period of 5 years. Interestingly, similar results were reported for lesionectomies in this cohort (56\%; [40]) and slightly lower rates for stereotactic laser thermoablation, a method increasingly used in North America [5, 19] because of its limited invasiveness in TLE (1-year follow-up, including repeat surgery, 53\% [16] and 58\%[44]).

Summarizing cohort studies (monoand multicentric, retrospective and prospective data acquisition) in TLE:

1. In shorter follow-up periods, seizure outcome seems to be less dependent on the surgical method (2-5 years). These findings have been replicated for TLE for longer follow-up periods (e.g., [17]), even though there is a tendency for larger removal to be beneficial [21].

2. There is a constancy in the decrease in the rate of seizure-free patients with the time of follow-up, which progresses slower over the years.

Tellez-Zenteno et al. summarized the results of 40 studies with a mean/median follow-up period of at least 5 years: In almost 3900 TLE patients, the seizure-free rate of the last follow-up was 66\% (independent of the surgical method; [39]). This number evidently summarizes the postsurgical seizure outcome of TLE patients with very variable follow-up periods and is, therefore, difficult to use for patient counseling. It is, however, important for comparison with other epilepsy syndromes.

So far, the majority of observational seizure outcome studies do not focus on extended follow-up periods [28, 39], i.e., at least 5 years or even longer periods. It seems inevitable, therefore, that these studies report heterogeneous results [28, $33,39]$ concerning the factors predicting seizure freedom. Interestingly, a cohort study by Janszky et al. [20] showed that prognostic factors may vary in the time course of the follow-up period [7].

The cohort of the present extra-longterm follow-up study has particular robust features such as a limited recruitment period of 5 years and successive, annual data acquisition for 10 years. The aim of this study was to determine prognostic factors for continuous seizure freedom over this period, with a particular focus on the time course of seizure freedom

\section{Methods}

\section{Subjects}

The study group comprised 60 patients who underwent consecutively resective surgery for TLE over a period of 60 months beginning 1 March 1993 to 28 February 1998 at the Epilepsy Center Berlin-Brandenburg, Germany. Patients were not offered presurgical evaluation 


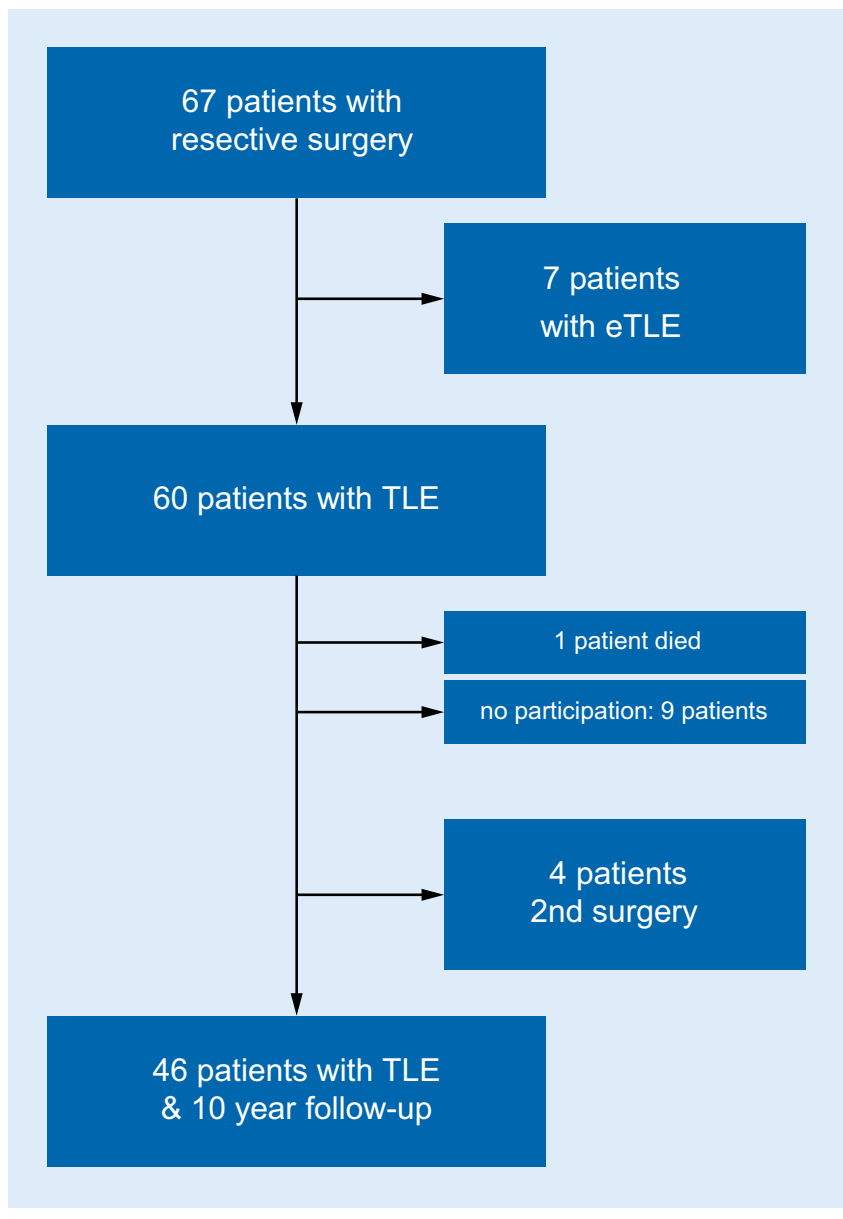

Fig. $1 \triangleleft$ Summary of patient cohort

if they were not pharmacoresistant to at least one antiepileptic drug (AED) for a period more than 1 year. Patients with brain lesions requiring instant surgery, active severe psychiatric comorbidity, or a full-scale IQ lower than 70 were excluded. All patients underwent a standardized presurgical workup including inpatient surface electroencephalographic (EEG) monitoring (1020 system up to 32 electrodes, usually for 7 days), standardized epilepsyspecific magnetic resonance imaging (MRI; $1.5 \mathrm{~T}$ ), neuropsychological testing, psychiatric and social assessment. All findings were discussed in a multidisciplinary case conference, after which conclusions about the eligibility for resective surgery or further diagnostic steps were drawn. If considered necessary, additional diagnostic investigations were added (interictal positron emission tomography [PET], single-photon emission computed tomography [SPECT], Wada test, dichotic hearing test, or EEG monitoring with foramen ovale/pegor subdural grid-electrodes). Surgery was performed by two board-certified neurosurgeons (JNL or WRL). Surgical pathology was analyzed routinely. A neurological examination and a cranial computer tomogram scan were performed 1 day after surgery.

\section{Study design}

Complete medical history and current seizure frequency, seizure type, AEDs, potential adverse effects (AE), and nonadherence (NA) were assessed before the surgical intervention. During out-patient visits 6 months, 12 months, and annually after surgery, these parameters and the seizure outcome, defined by Engel's classification of postsurgical outcome [10], were followed up prospectively. The classification of the International League Against Epilepsy (ILAE; [43]) by Wieser et al. was not available at the beginning of this study. Seizure types were classified according to the ILAE classification that was current at the time of data acquisition [47]. Seizures occurring less than 4 weeks after surgery were classified as perioperative as opposed to recurrence of seizures after this time period. Presurgical AEDs were continued after surgery for at least 2 years. Only in the case of AE or unprovoked recurrence of seizures was the dosage adjusted or an additional AED prescribed. Patients documented seizure-like events in seizure diaries and detailed oral descriptions were obtained from patients and, if possible, from witnesses during the yearly follow-up visits. If previous and current EEGs were not suggestive of an active epileptogenic focus, tapering of one AED for one third of the daily dosage was allowed. To minimize an observational bias error, all patients were seen by at least four of the following five certified epileptologists: CD, HJM (author), MM, FCS (author) and HBS. If a pre-scheduled follow-up (FU) visit failed, a semi-structured telephone interview was conducted and a new visit was scheduled.

Primary outcome was seizure freedom over a period of 10 years. The authors defined a "successful" surgery if the patient's condition was continuously classified as Engel Class I for this observation period. This approach was chosen because even rare seizure recurrence can be considered a failure in view of the high psychosocial impact of the seizures themselves.

Secondary outcome was the perpetuation of the individual patient's seizure class. To analyze the course of seizure freedom, patients were subdivided into five groups:

- Group 1= "successful" surgery= retention of Engel Class I for the 10 years

- Group 2= "running down" = continuous enhancement of seizure outcome with subsequent achievement of Engel Class I

- Group 3 = "running up" = initially Engel Class I, with successive worsening

- Group 4= "mixed" = within the 10 years FU, at least 1 year of Engel Class I

- Group 5= no seizure freedom for 10 years $=$ Engel Class II-IV. 
Z. Epileptol. 2020 ·33:50-61 https://doi.org/10.1007/s10309-019-00302-x

(c) The Author(s) 2019

\section{F. C. Schmitt · H. Meencke}

\section{Factors predicting 10-year seizure freedom after temporal lobe resection. A monocentric, continuous extra-long-term evaluation}

\section{Abstract}

Background. Resective surgery is an established and evidence-based treatment approach in pharmacoresistant temporal lobe epilepsy (TLE). Extra-long-term follow-up data are important to allow for good patient counseling. So far, only few trials provide prospective or retrospective data exceeding 5 years.

Objective. This study aimed to present data of continuous seizure outcome over an extended time period, with a particular focus on patients who remained seizure free for 10 years. Methods. We analyzed seizure outcome after epilepsy surgery for TLE in 46 consecutive patients, who were seen on an annual basis for 10 years in a single center (Epilepsy Center Berlin Brandenburg). Factors for remaining seizure free for 10 years were determined by univariate analysis.

Results. The class I outcome changed each year by $74-78 \%$. Of the patients, $63 \%$ remained continuously in Engel class I (48\% Engel Class IA for 10 years) for 10 years. Six patients were never seizure free (12.5\%). After 10 years, $35 \%$ of the patients were cured (i.e., seizure-free without medication). A higher number of antiepileptic drugs and seizures before surgery as well as the indication for invasive presurgical monitoring were associated with "unsuccessful surgery."
Conclusion. With almost half of the patients completely seizure free and more than a third "cured," epilepsy surgery remains the mainstay of therapy for TLE patients. Analysis in larger cohorts with extra-long-term follow-up is needed to assess good prognostic factors and other postsurgical outcome issues such as neuropsychological, psychiatric, and psychosocial outcomes.

Keywords Epilepsy · Long-term follow-up · Seizure outcome · Resective · Cure

\section{Prognosefaktoren einer 10-Jahres-Anfallsfreiheit nach Temporallappenresektion. Eine monozentrische, kontinuierliche Extra-Langzeituntersuchung}

\section{Zusammenfassung}

Hintergrund. Die resektive Epilepsiechirurgie ist ein etabliertes Verfahren zur Behandlung der pharmakoresistenten fokalen Epilepsie mit Ursprung im Temporallappen (TLE). Extra-Langzeitverlaufsdaten sind wichtig für eine gute Patientenberatung, allerdings sind bislang nur wenige prospektive oder retrospektive Untersuchungen mit einem Beobachtungszeitraum von länger als 5 Jahren publiziert worden.

Ziel der Arbeit. Ziel war die Präsentation der Ergebnisse bzgl. der Anfallsfrequenz bei operierten TLE-Patienten über einen längeren Zeitverlauf mit einem besonderen Schwerpunkt auf den Patienten, die über mindestens 10 Jahre anfallsfrei waren. Material und Methoden. Die Autoren analysierten Daten zum Anfalls-Outcome von 46 aufeinanderfolgenden Patienten mit
Zustand nach Resektion, welche jährlich in einem tertiären Epilepsiezentrum (EpilepsieZentrum Berlin-Brandenburg) untersucht wurden. Faktoren für eine 10-jährige Anfallsfreiheit wurden durch eine univariate Analyse bestimmt.

Ergebnisse. In jedem einzelnen Jahr schwankte der Anteil von anfallsfreien Patienten zwischen 74 und $78 \%$. Während des gesamten Beobachtungszeitraums von 10 Jahren verblieben $63 \%$ der Patienten in der Engel-Klasse I und $48 \%$ in der EngelKlasse IA. Kein Jahr mit Anfallsfreiheit wurde bei 6 Patienten (12,5\%) festgestellt. Nach 10 Jahren waren etwa 35\% der Patienten "geheilt" (d. h. anfallsfrei ohne antiepileptische Behandlung). Eine erhöhte Anzahl von Antiepileptika oder Anfällen vor der Operation und die Indikationsstellung für ein invasives Verfahren waren signifikante Faktoren für eine nicht erfolgreiche Operation. Schlussfolgerung. Das Ergebnis von fast $50 \%$ komplett anfallsfreien und mehr als ein Drittel "geheilter" Patienten belegt, dass die Epilepsiechirurgie eine wichtige therapeutische Maßnahme bei pharmakoresistenter TLE ist. Analysen von größeren Kohorten mit einem Extralangzeitverlauf sind notwendig, um relevante Faktoren für das Ziel "Anfallsfreiheit" und andere Parameter aus neuropsychologischen, psychiatrischen und psychosozialer Befunden bestimmen zu können.

Schlüsselwörter Epilepsie - Langzeitverlauf - Anfalls-Outcome . Resektiv $\cdot$ Heilung
Patient selection is delineated in • Fig. 1 and detailed data, before presurgical evaluation (e.g., clinical details and etiology according to MRI), the mode of presurgical and surgical procedures (e.g., surface vs. invasive monitoring; resection methods) of the patient cohorts are summarized in $\bullet$ Table 1.

The analyzed variables obtainable before and after the presurgical evaluation and after surgery are summarized in - Table 2. They were chosen according to the generally accepted decision process for resective surgery. Presurgical occurrence of auras and focal to bilateral tonic-clonic seizures were regarded as a separate variable. For baseline seizure frequency, focal impaired awareness seizures (according to ILAE classification from 1981: complex partial seizures) and focal to bilateral tonic-clonic seizures (according to ILAE classification from 1981: secondarily generalized seizures) from the last 3 months prior to surgery were averaged. The authors consider the term "aura" as important in the context of epilepsy surgery, therefore they will use "aura" in this manuscript, even though the current classification [12-15] would classify this seizure-type as "focal aware seizure." Electroclinical, neuropsychological, psychiatric, and social outcome parameters are not addressed in this study. 
Table 1 Clinical details of whole cohort (including extratemporal lobe epilepsies) and of study group (only temporal lobe epilepsies without re-resection)

\begin{tabular}{|c|c|c|c|c|c|}
\hline & & \multicolumn{2}{|c|}{ All $=67$} & \multicolumn{2}{|c|}{ Study group $=46$} \\
\hline & & Mean & SD & Mean & SD \\
\hline \multicolumn{2}{|l|}{ Minimum follow-up } & 9.2 & 2.5 & 10.3 & 0.1 \\
\hline Sex & Female & 33 & - & 25 & - \\
\hline \multirow[t]{4}{*}{ Age } & Age at surgery & 30.5 & 12.7 & 2.4 & 12.5 \\
\hline & Younger than 18 & 16 & - & 9 & - \\
\hline & Epilepsy duration & 17.6 & 13.4 & 19.3 & 13.8 \\
\hline & First seizure & 13.2 & 9.8 & 13.0 & 10.3 \\
\hline Side & Left & 38 & - & 26 & - \\
\hline \multirow[t]{4}{*}{ Location } & FLE & 4 & - & 0 & - \\
\hline & Multifocal epilepsy & 3 & - & 0 & - \\
\hline & mTLE & 32 & - & 26 & - \\
\hline & Temporal epilepsies (other) & 28 & - & 20 & - \\
\hline \multirow[t]{3}{*}{ Invasiveness } & Surface & 43 & - & 27 & - \\
\hline & Peg/foramen ovale electrode & 5 & - & 4 & - \\
\hline & Grids & 19 & - & 13 & - \\
\hline \multirow[t]{5}{*}{ OP region } & Temporo-anterior & 46 & - & 37 & - \\
\hline & Temporo-lateral & 9 & - & 7 & - \\
\hline & Temporal others & 5 & - & 2 & - \\
\hline & Frontal & 6 & - & 0 & - \\
\hline & Hemispherical & 1 & - & 0 & - \\
\hline \multirow[t]{6}{*}{ OP procedure } & aTLR & 52 & - & 40 & - \\
\hline & aTLR extended & 3 & - & 3 & - \\
\hline & Lesionectomy & 5 & - & 1 & - \\
\hline & Partial cortectomy & 2 & - & 1 & - \\
\hline & Partial frontal lobectomy & 2 & - & 0 & - \\
\hline & Others & 3 & - & 1 & - \\
\hline \multirow[t]{3}{*}{$\mathrm{PMHx}$} & Febrile seizures & 10 & - & 8 & - \\
\hline & Epilepsy in family & 10 & - & 7 & - \\
\hline & Psychiatricillness & 20 & - & 9 & - \\
\hline \multicolumn{2}{|l|}{ Seizure frequency } & 8.6 & 12.2 & 7.4 & 8.6 \\
\hline \multirow[t]{3}{*}{ AEDs } & No AED after 10 years & 22 & - & 21 & - \\
\hline & Non-adherence & 18 & - & 12 & - \\
\hline & Number in lifetime & 3.6 & 1.9 & 3.6 & 1.8 \\
\hline \multirow[t]{3}{*}{ Semiology } & Auras & 38 & - & 29 & - \\
\hline & BTCS & 47 & - & 33 & - \\
\hline & SE & 2 & - & 2 & - \\
\hline
\end{tabular}

\section{Statistical analysis}

For the Kaplan-Meier event-free survival, curves were determined and differences between subgroups were evaluated with the generalized Wilcoxon test. Patient outcome was classified into "successful" surgery (Group 1) and "unsuccessful" surgery (Groups 2-5). Differences in metric variables between the "successful" surgery group vs. the cumulated "unsuccessful" surgery groups assess the parametric vs. non-parametric distribution. Differences were considered significant at $p<0.05$. Data are given as mean \pm SD. Statistical calculations were performed using PASW 19.0.

\section{Results}

Altogether, 60 consecutive patients (29 female, 48.3\%) had surgery between 1 March 1993 and 28 February 1998. Surgical procedures comprised classic anterior or extended temporal lobe resection (91.7\%), lesionectomy (5.0\%), partial lobectomy or cortectomy $(1.6 \%)$, and others (1.6\%). A total of 37 patients $(61.7 \%)$ had surgery on the left hemisphere. The age range was from 10 years to 57 years (mean 32.1 years, $\mathrm{SD}=12.2)$.

\section{Patients lost to continuous follow- up}

One patient ( $1.7 \%$ of 60 TLE patients) died after the sixth follow-up visit. Death was unexpected and unexplained and therefore "sudden unexpected death in epilepsy" (SUDEP) was suspected. Postsurgical outcome had steadily been classified as Engel Class II before. One patient did not attend follow-up visits, since the first visit 6 months after surgery.

Continuous study participation failed in ten patients ( $16.7 \%$ of 60 TLE patients; - Fig. 1). Seven (11.7\% of 60 patients) of these patients attended follow-up visits for 2 years (details • Fig. 2), so that a fairly robust approximation of seizure outcome was not available for the remaining three patients (5.0\% of 60 TLE patients). The median continuous follow-up of the then patients lost to follow-up was 3.16 years $(\mathrm{SD}=2.7)$, and five out of nine $(55.6 \%)$ patients achieved Engel Class I at the last outcome visit (• Fig. 2).

From the remaining 50 patients, a complete postsurgical follow-up could be obtained. If presurgical re-assessment was suggestive of possible improvement of seizure control by re-resection, patients were offered another resection. Therefore, four patients had to be excluded, because re-resection was per- 


\section{Table 1 (Continued)}

\begin{tabular}{|c|c|c|c|c|c|}
\hline & & \multicolumn{2}{|c|}{ All $=67$} & \multicolumn{2}{|c|}{ Study group $=46$} \\
\hline & & Mean & SD & Mean & SD \\
\hline \multirow[t]{13}{*}{ Etiology by MRI } & HS & 18 & - & 13 & - \\
\hline & FCD & 8 & - & 5 & - \\
\hline & Cortical malformations (other) & 8 & - & 7 & - \\
\hline & Oligodendroglioma & 1 & - & 0 & - \\
\hline & Ganglioglioma & 3 & - & 2 & - \\
\hline & DNET & 3 & - & 2 & - \\
\hline & Hamartoma & 4 & - & 3 & - \\
\hline & Tumor (other) & 5 & - & 4 & - \\
\hline & Cavernoma, single & 2 & - & 1 & - \\
\hline & Cavernoma, multiple & 2 & - & 1 & - \\
\hline & Posttraumatic & 1 & - & 1 & - \\
\hline & Post-stroke & 1 & - & 0 & - \\
\hline & Others & 11 & - & 7 & - \\
\hline $\begin{array}{l}\text { HS confirmed in } \\
\text { pathology }\end{array}$ & - & 22 & - & 15 & - \\
\hline \multicolumn{6}{|c|}{$\begin{array}{l}\text { LE frontal lobe epilepsy, } m T L E \text { mesial temporal lobe epilepsies, aTLT anterior temporal lobe } \\
\text { resection, } O P \text { resective surgery, } P M H x \text { past medical history, } A E D \text { antiepileptic drugs, BTCS bilateral } \\
\text { tonic-clonic seizures, SE status epilepticus, } M R I \text { magnetic resonance imaging, } H S \text { hippocampal } \\
\text { sclerosis, } F C D \text { focal cortical dysplasia }\end{array}$} \\
\hline
\end{tabular}

Table 2 -Values for all analyzed variables comparing the "successful" surgery group (i.e. patients experiencing postsurgically exclusivly auras or continous seizure freedom) and the "unsuccessful" surgery groups (i.e. patients with seizures others than auras after the resection)

Variables before presurgical work-up

Sex

Age at surgery 1

Age at 1st seizure 0.211

Duration of epilepsy

Previous psychiatric illness

Family history of epilepsy

0.998

1

0.517

Febrile seizures

0.431

Mean number of AEDs before surgery $\quad 0.005^{\circ}$

$\begin{array}{ll}\text { Non-adherence } & 0.722\end{array}$

Hippocampus sclerosis on MRI $\quad 0.516$

Mean number of seizures 3 months before surgery $\quad 0.049^{\mathrm{a}}$

Seizure semiology includes aura

0.336

Seizure semiology includes focal to BTCS

1

Known status epilepticus

0.137

Variables during and after presurgical work-up

Invasive monitoring

$0.0279^{\mathrm{a}}$

(i.e., peg/foramen ovale electrodes and/or grid)

Left vs. right

1

Operation site (mTLE vs. others TLE)

0.443

Variables during and after surgery

Transient surgical complications

0.493

Etiology in pathology

0.5949

Hippocampal sclerosis in pathology

1

$M R I$ magnetic resonance imaging, BTCS bilateral tonic-clonic seizure, $m T L E$ mesial temporal lobe epilepsies

${ }^{a}$ Statistically significant valus formed within the 10-year follow-up period.

A total of 46 patients $(76.7 \%$ of $60 \mathrm{TLE}$ patients) were included in the final statistical analysis of this study. For further patient details, see $\bullet$ Table 1.

The distribution of the Engel classification in each consecutive year is shown in - Fig. 3. The proportion of patients classified as Engel Class I ranged from 70.0 to $72.0 \%$ (median: $70 \%, \mathrm{SD}=0.97$ ), Engel Class II from 6.0 to 10.0 (median $8.0 \%, \mathrm{SD}=1.75)$, Engel Class III from 6.0 to $14.0 \%$ (median $8.0 \%, \mathrm{SD}=2.07$ ), and Engel Class IV from 0 to $4.35 \%$ (median $0.87 \%, \mathrm{SD}=0.82$ ).

\section{Seizure freedom over 10 years}

\section{Kaplan-Meyer survival rate}

Out of 46 patients, 29 (63.1\%) remained continuously in Engel class I (group 1) (- Fig. 4a). The survival rate for seizure freedom of all 60 patients with TLE (i.e., including the patients lost to continuous follow-up) is shown in • Fig. 4b. For the latter analysis, patients who were lost to continuous follow-up were censored after their last follow-up visit and patients who had had a re-operation were censored before this intervention. Another three patients achieved continuous seizure freedom after 1-5 years (mean: 3 years; group 2).

\section{Successful vs. unsuccessful surgery}

As outlined in the Method section, the cohort was divided into two groups: the "successful" surgery (i.e., group 1) sustaining Engel Class I classification for 10 years and the "unsuccessful" surgery group (i.e., groups 2-5). The following preoperative factors predicted seizure freedom over 10 years: the number of AEDs that had been taken by the patients prior to surgery (mean $3.2 \pm 1.3$ in the successful group vs. $4.7 \pm 1.3$ in the unsuccessful group, $p<0.05$ ) was significantly lower, the number of seizures prior to surgery (median $5.3 \pm 2.3$ in the successful surgery group vs. $11.9 \pm 3.5$ in the unsuccessful surgery group, $p<0.01$ ) was significantly lower, and patients who needed invasive recordings had a significantly lower chance of obtaining complete seizure freedom $(41 \%$ in patients 


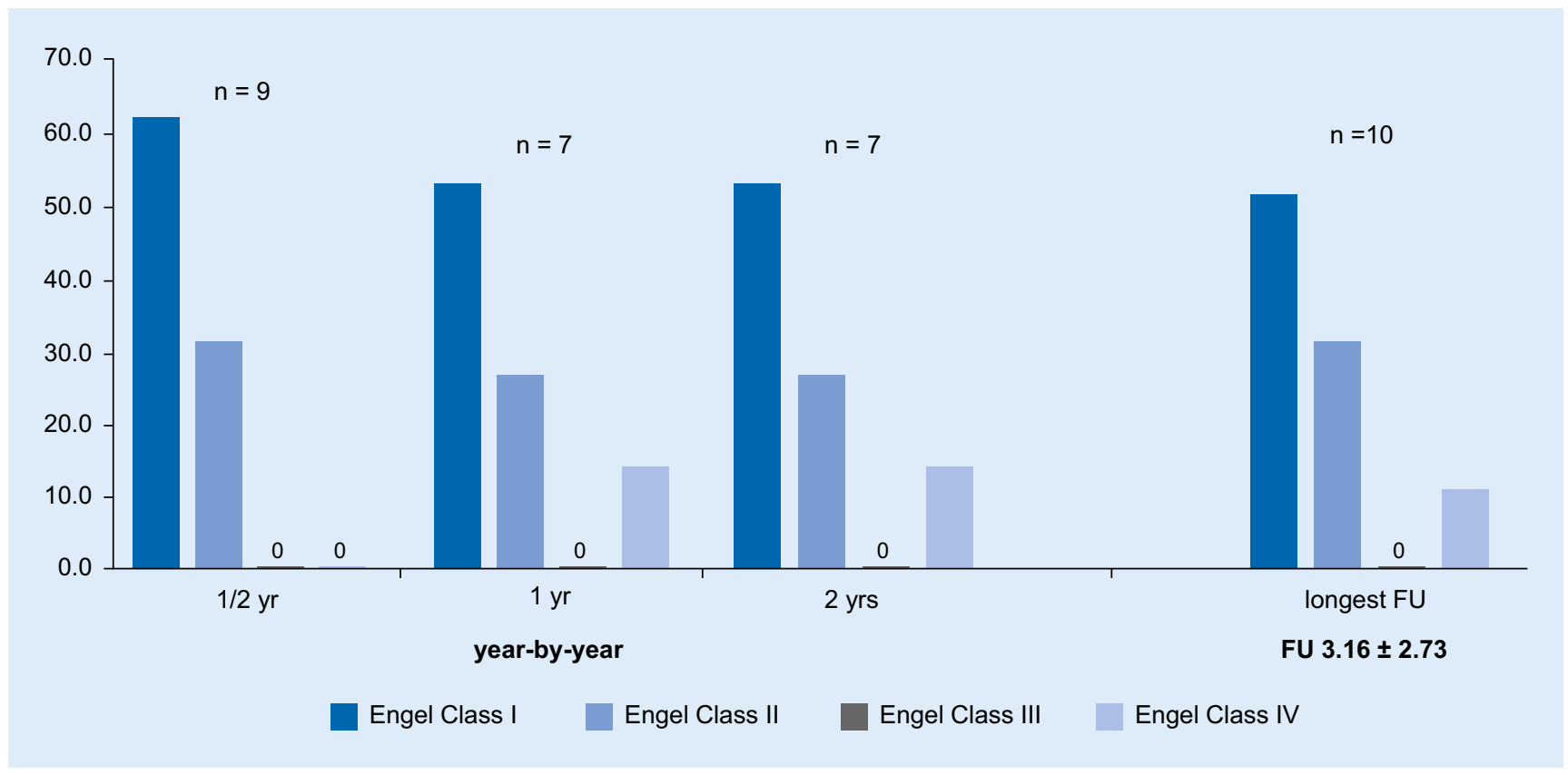

Fig. $2 \Delta$ Follow-up of patients without study participation

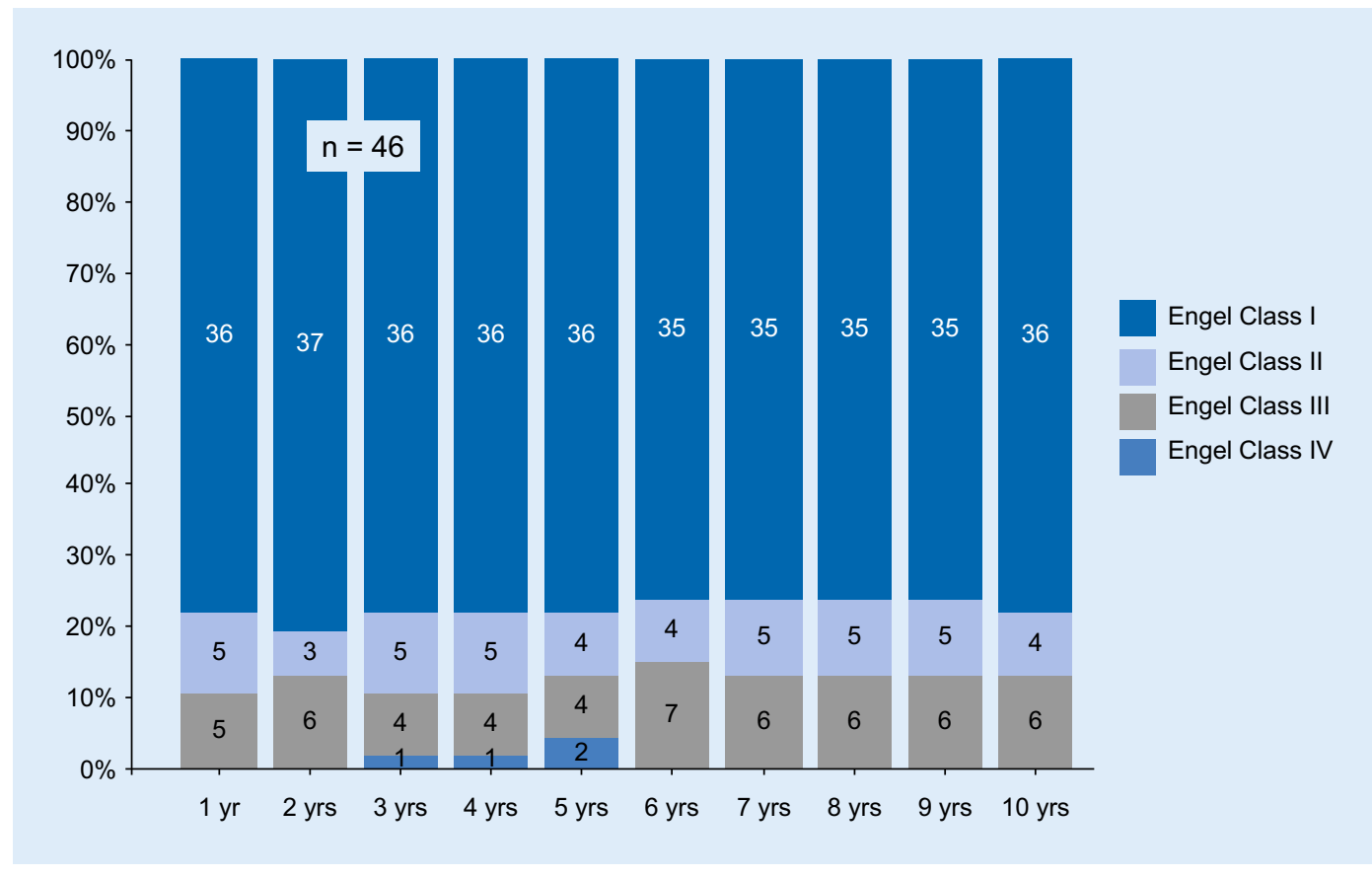

Fig. $3<$ Year-by-year follow up of patients with temporal lobe epilepsy

with invasive recordings vs. $76 \%$ in patients without invasive recordings; see - Fig. 5). The latter results were supported by a significant difference in the survival rate toward seizure freedom during the 10-year follow-up period in patients who had to have invasive recordings (see • Fig. 6).

The $p$ values for all analyzed variables comparing the "successful" surgery group and the "unsuccessful" surgery groups are summarized in • Table 2.

\section{Perpetuation of postoperative seizure class}

From the 29 patients classified as having successful surgery (i.e., retention of Engel Class I), 22 patients (47.8\% from 46 patients) had no seizure including auras
(Engel Class IA). Three patients ("running down" = group 2) showed a continuous improvement reaching Engel Class I (mean $6.3 \pm 2.5$ years of Engel Class I, from 4 to 9 years) In three patients there was an opposite phenomenon: They were initially classified Engel Class I (mean $4.17 \pm 1.16$ years of Engel Class I, from 4 to 6 years), with successive seizure recurrence. Six patients (group $4=$ "mixed") 

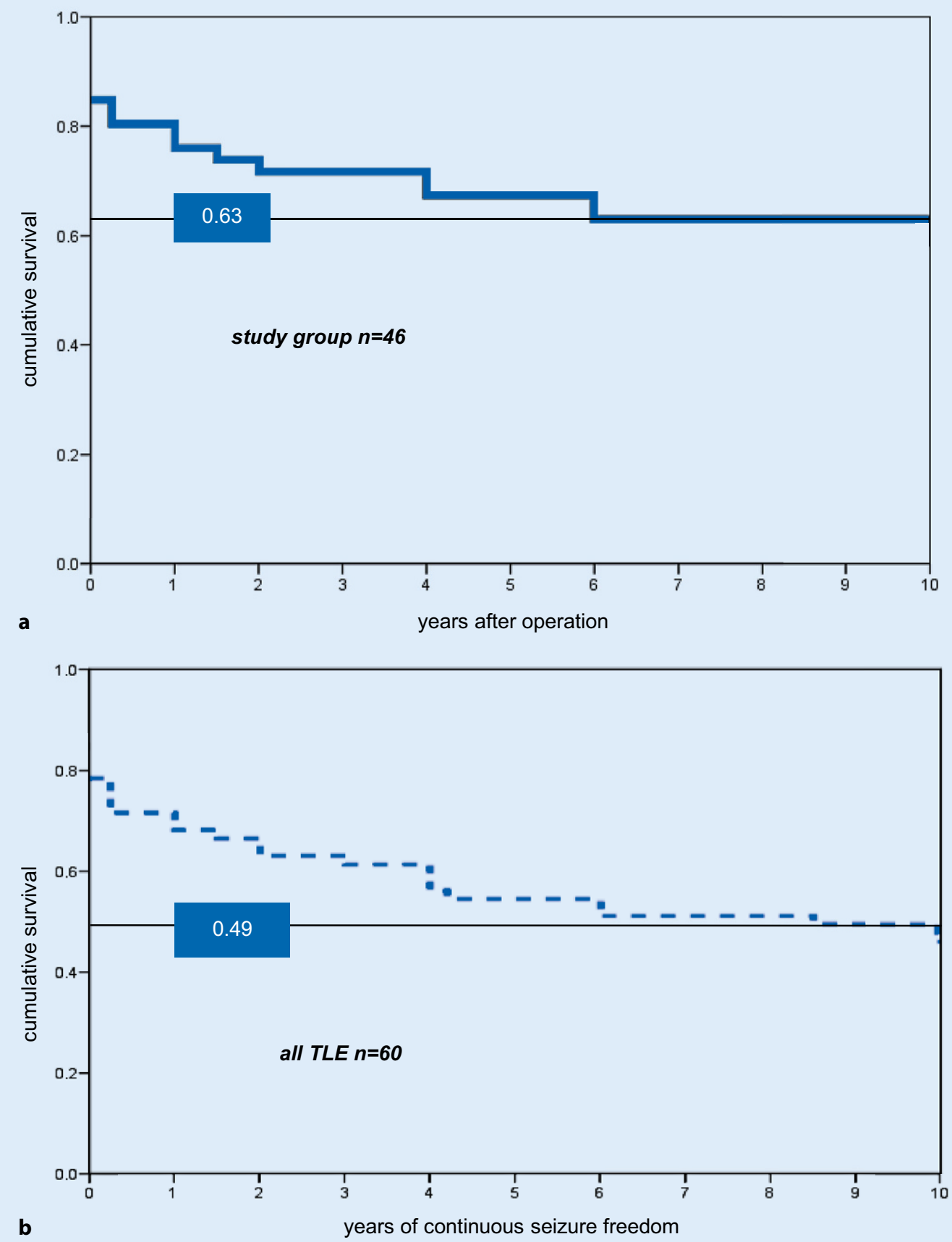

Fig. $4<$ Kaplan-Meier survival analysis:years of continuous seizure freedom (Engel Class I). TLE temporal lobe epilepsy

were classified as Engel Class I for at least 1 year (mean $5.5 \pm 2.6$ years of Engel Class I, from 1 to 8 years); there was, however, neither terminal remission of seizures nor constant worsening. Five patients never achieved a year of seizure freedom (group $5=$ no seizure freedom).

\section{Successful surgery in relation to AED medication}

Out of the 29 patients with successful surgery (i.e., 10 years of Engel Class I), 16 (34.8\% of all 46 study patients) experienced not only full remission but at least a "resolution" or likely a "cure" [11]: They did not take any AED during the last 3-10 years of continuous follow-up (mean $6.6 \pm 2.4$ years). Four of these pa- tients $(25.0 \%$ of 16 cured patients) did not adhere to the treatment plan and discontinued AED medication abruptly. They were seizure free and AED free for 8-10 years (mean $9.3 \pm 0.7$ years). Nonadherence was prevalent in the successful surgery group at a rate of $24.1 \%$ (seven patients) and at a rate of $35.3 \%$ (six patients) in the unsuccessful surgery. Univariate analysis for patients with successful surgery on AED and cured patients did 


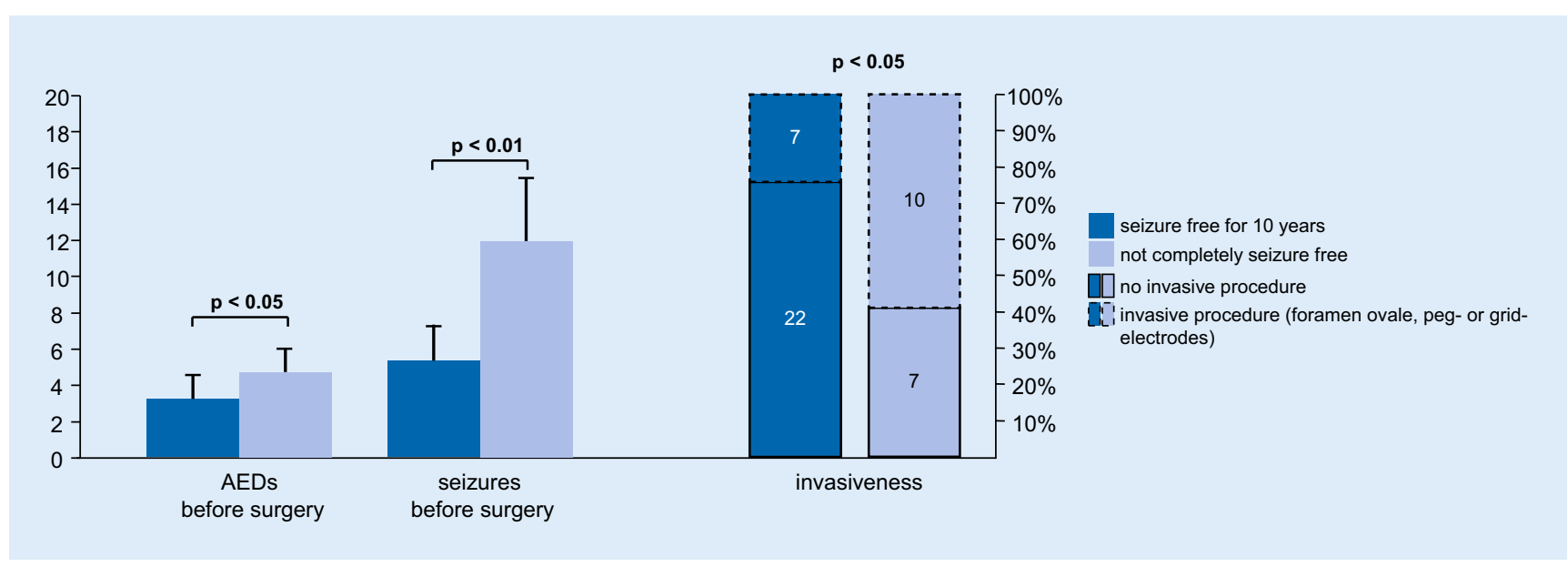

Fig. 5 ム Left: Number of antiepileptic drugs (AEDs) and seizure before surgery in "successful" surgery (dark blue) and "unsuccessful" surgery (light blue) groups. Right: Proportion (absolute numbers in column) of patients with or without invasive presurgical monitoring in successful surgery (darkblue) and unsuccessful surgery groups (light blue)

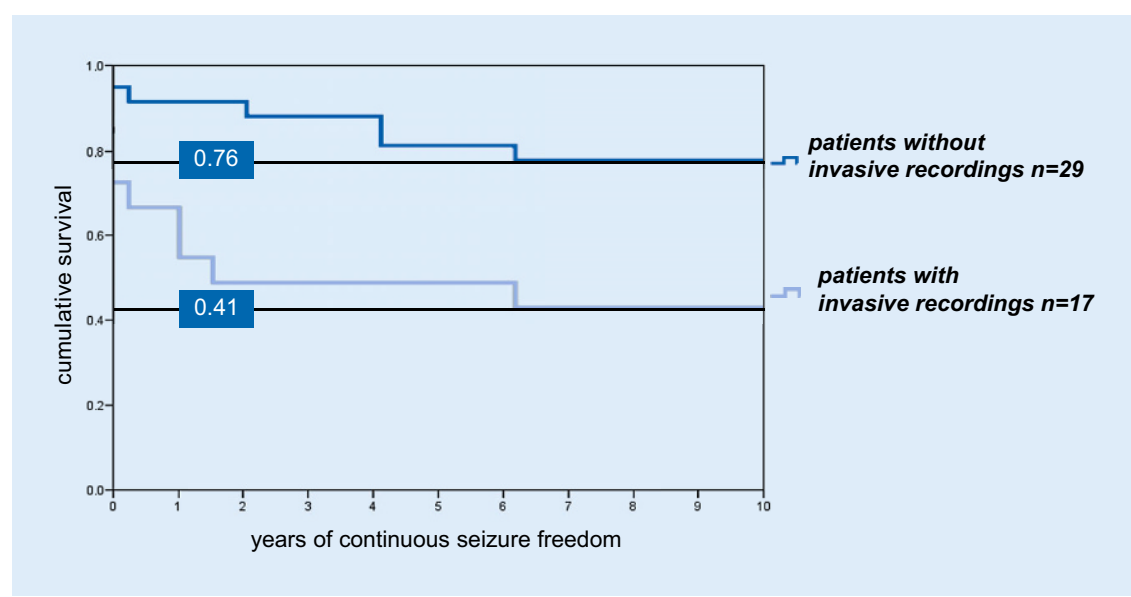

Fig. 6 ム Kaplan-Meier survival analysis

not reveal any discriminating factors. An additional three patients (group 2, "running down") achieved continuous seizure freedom within 5-9 years, all of them by adding an additional AED and never without AEDs.

\section{Discussion}

The presented cohort of TLE patients who received resective surgery was followed up clinically on an annual basis. The primary outcome of seizure freedom over a period of 10 years was deliberately chosen because even rare seizure recurrence is a failure in view of the potential negative psychosocial impact. Most importantly, factors predicting a successful surgery on a long-term basis are important for patient counseling.
This monocentric extra-long-term follow-up study observed a homogeneous patient group with robust features, because:

1. Of the rather short recruitment period of 5 years, the same diagnostic and surgical techniques were used.

2. The recruitment period ended in February 1998, so that all patients had a comparable history of previously available AEDs excluding the so-called new second- and thirdgeneration medications [25].

3. The 60 TLE patients were prospectively invited to an outpatient followup visit annually, a management procedure that has had the advantage of obtaining regular data and probably added to this robust data set.
The main five findings were:

A. The change of seizure freedom for TLE patients after resective surgery is $63 \%$ (49\% strictly including all patients for follow-up).

B. The chance to become seizure free for 1 year (annual follow-up) ranged solidly between 76 and $80 \%$.

C. In a univariant analysis the number of seizures and the number of AEDs prior to surgery were a negative predictive factor for achieving 10 years of seizure freedom.

D. In this particular cohort the decision in the multidisciplinary case conference to advise for invasive monitoring (peg or foramen ovale electrodes or grids) because of a more complex network disturbance was associated with a noticeable drop in the seizure rate from 76 to $41 \%$.

E. More than one third of patients were cured in the sense of obtaining seizure freedom without AED medication.

\section{Patients lost to follow-up and postoperative long-term seizure outcome}

Most of the findings are in line with previous publications on resective surgery.

Concerning the rate of patients lost to follow-up, both de Tisi et al. [40] with more than 500 TLE patients and Aszetly et al. [1] with their predominantly extra-long-term study (mean follow-up of 12.4 years) had a similar rate of $5 \%$ of pa- 
tients, where no data at all were available. Both study groups obtained their data from a prospectively maintained central database, suggesting that a monocentric prospective data collection-similar to our cohort-supports extra-long-term data acquisition. Aszetly et al. presented data with extra-long-term follow-up of at least 8.6 years from 65 patients after resective surgery (both temporal and extratemporal epilepsies). The rate of patients lost to follow-up who did not reach the 10 -year margin was slightly higher at $18 \%$, compared with our rate of $12 \%$. In their cohort the last follow-up had a seizure-free rate in patients with temporal lobe resection of $65 \%$, comparable to the $63 \%$ in our study. The de Tisi cohort of 537 TLE patients achieved Engel Class I outcome either by temporal lobe resection (55\%) or lesionectomies (56\%) after 5 years [40]. In view of the expected decrease within the following 5 years, this seizure rate estimate seems rather conservative. However, apparently most of their TLE patients were lost to followup in the first year after surgery, so that a recruitment deficit might explain the lower number. Interestingly, they also found a high rate of $82 \%$ of patients who achieved Engel Class I for at least 1 year at some stage of their extended long-term follow-up period.

\section{Prognostic factors for successful surgery assessed before presurgical work-up}

Téllez-Zenteno et al. [39] in their metaanalyses found that for all resective types of surgery, the long-term seizure freedom was highest in patients with tumoral epilepsy, lowest in studies of patients older than 50 years at the time of surgery, as well as in older studies and in those with and extra-long-term followup of 10 years. Several studies suggest that the age (i.e., the duration of uncontrolled epilepsy; $[6,34,45])$, the severity (e.g., preoperative seizure frequency; [6, $22,27])$, and the functional extent of the epileptogenic network (EEG data or existence of focal to bilateral tonic-clonic seizures; cortical malformation; [6, 20, 34]) have an impact on seizure outcome. It is well accepted that a difficult-to-local- ize or a non-lesional epileptogenic network (e.g., the lack of an epileptogenic lesion on the preoperatively MRI) is a stable negative predictor $[6,20,22,23,27$, $34,35,45]$. Concerning the predictive factors for long-term seizure freedom, several factors have been suggested; unfortunately, in most cases with a followup period of less than 5 years. In Sweden, all epilepsy surgery procedures after 1989 are reported to a central database, so that Edelvik et al. [6] were able to analyze the long-term follow-up seizure outcome (minimum 5 years) after resective surgery in a large cohort of 190 patients with temporal and extra-temporal epilepsies. In their multivariant analysis, they found that:

1. The detection of an epileptogenic lesion on the MRI and a temporal site of the epileptogenic network are good prognostic factors.

2. And more importantly, the duration of the epilepsy, the preoperative seizure frequency, and the existence of cortical malformation or gliosis are negative predictors for seizure outcome.

Retrospectively, the detection of an MRI lesion was not prognostic in our cohort, probably due to the limited sensitivity and experience with technology available at that time instead of the new MRI technology. Concerning the severity of the individual patient's epileptogenic network disturbance, in our cohort we also found that the number of preoperative seizures was a predictor for negative outcome. It is conceivable that the number of AEDs in the patient's previous history are also an expression of the severity-and possibly of the age of-the individual epileptogenic network. To our knowledge, the number of AEDs prior to surgery has yet not been thoroughly investigated in the context of resective epilepsy surgery. There are, however, few studies that suggest that the postoperative AED regimen has an impact on the patients [20,46].
Prognostic factors for successful surgery assessed during presurgical work-up

As outlined in - Table 2, "invasive monitoring” (i.e., peg/foramen ovale electrodes and/or grid) was the only factor to have a negative impact on postsurgical outcome. The site of surgery-mesial vs. lateral or left vs. right-did not have an impact.

In our cohort, the chance of having a successful surgery was reduced almost by half from 76 to $41 \%$, if the multidisciplinary case conference advised invasive monitoring (i.e., peg/foramen ovale electrodes and/or grids). Acknowledging the growing numbers of patients who both are advised to accept invasive monitoring and are reluctant to undergo invasive procedures [2], this aspect seems increasingly important for patient counseling. However, only a few cohort studies have provided comparative seizure outcome data of patients who were perceived to need invasive monitoring. Pooled data of different epilepsy syndromes and different follow-up periods showed that there was a $72 \%$ change of seizure freedom for patients without invasive monitoring and a 59\% change with invasive monitoring [41]. Nevertheless, in 866 patients with non-lesional TLE, Mariani et al. did not find any difference in outcome in the univariate analysis whether stereo-EEG was used or not [26].

Generally, all monocentric resective surgery outcome studies have a centerspecific bias concerning their decisions in the multidisciplinary case conference, especially regarding the choice of diagnostic measurements. Our result probably reflects the conservative approach of the epilepsy center with a general tendency toward noninvasive diagnostic tools, so that only patients with a difficult-to-localize epileptogenic network had invasive monitoring. This view was shared in a large meta-analysis of 782 patients from 36 studies who received repeat resective epilepsy surgery [24]. 
The chance of cure after temporal lobe epilepsy surgery

The chance of cure is an important motivation for patients to undergo presurgical evaluation, possibly invasive monitoring, and subsequent resection $[18,29,36]$. Of our 29 patients who remained seizure free for 10 years (group 1, "successful" surgery), 16 (35\% of our 46 study and $55 \%$ of all patients in group 1) had a curative resection: They remained seizure free even though they did not take AEDs for 3-10 years of continuous follow-up. In view of the strict criteria of " 10 -year seizure freedom," our finding (55\% cured patients of all postsurgically seizure-free patients) can be viewed in line with those of Schmidt et al. [32]: In their literature review on predominantly TLE patients, AED discontinuation was successful (i.e. no seizure recurrence) in $66 \%$ of the patients, who were rendered seizure free by epilepsy surgery before (maximum follow-up of 1-5 years).

\section{Limitations and outlook}

Several limitations of the data presented in this study should be considered. Even though only a few patients were lost to follow-up and the continuous follow-up visits on an annual basis yielded a robust data set, the sample size is rather modest. Also, in this study we used only univariate statistics. Most importantly, we did not compare our results with best medical treatment group with AED treatment. Furthermore, the results are from a single center, so that-as discussed-centerspecific decisions might be mirrored in the findings. However, only very few studies have carried out extra-long-term follow-up (i.e., 10 years) and all of them were single-center studies. In most follow-up studies, a considerable loss of patients to follow-up over time dominates the data, so that factors predicting seizure outcome are possibly flawed. The assement of these factors-especially those relating to the time before or during the presurgical work-up-is of particular importance.

Follow-up visits are part of the national quality guidelines for presurgical epilepsy diagnosis and operative epilepsy therapy $[30,31]$. In our view, the collection of (extra-)long-term follow-up data enhance the quality management by every tertiary center performing resective (or other invasive or minimally invasive) procedures: Follow-up data over an extended period of time would allow more data to be collected about the proportions of patients who are cured (i.e., seizurefree without AED) after a surgical procedure. After all, cure is the best postsurgical result, followed by complete seizure freedom including auras. It would be beneficial to examine these endpoints on a regular basis, because:

1. From the perspective of the patients it is an important motivation to become not only seizure free but also medication free.

2. The concept of complete removal of the epileptogenic network requires this information.

In our cohort, resection led to complete removal of the epileptic network in nearly half of the patients. In view of these two key results, the authors regret that the postsurgical outcome classification of the ILAE [43] has not reached overall acceptance in the literature, because this outcome classification has-among others - the important advantage of accrediting "complete seizure freedom" its own category (Engel Class IA versus ILAE Class 1).

\section{Conclusion}

Our results underline that resective surgery of carefully chosen patients remains the mainstay of therapy and that a thorough follow-up with several periods should be the gold standard for nonreversible surgical procedures. There seem to be distinct subgroups of surgery failures (i.e., groups 2-5) and of surgery "winners" (i.e., "cured" patients). Further analysis is needed to also assess other outcome issues such as neuropsychological, psychiatric, and psychosocial outcome. Larger groups in a preferably controlled design are needed so as to assess factors that predetermine which patients might belong to which of the five aforementioned groups.

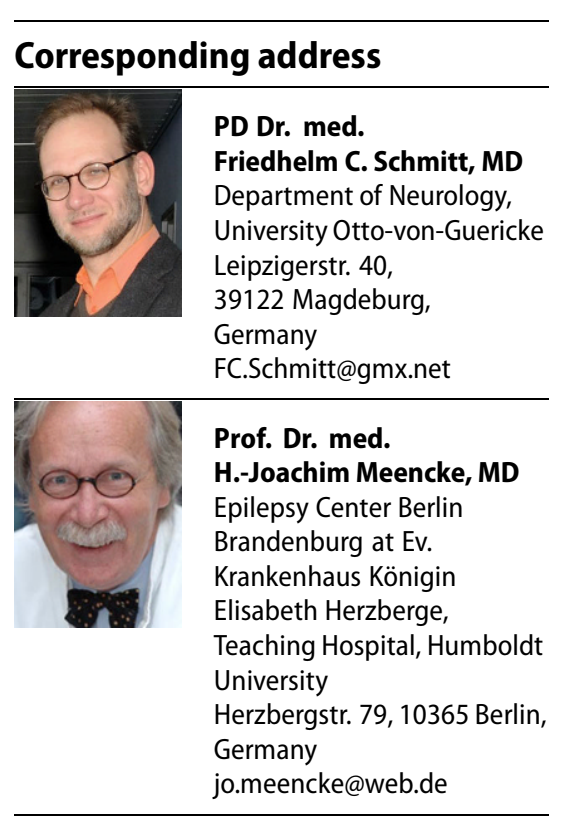

Acknowledgements. We thank the following contributors for their participation: D. Meinken-Jäggi (data acquisition), F. Oltmanns, MA (data acquisition and manuscript proofreading), C. Dehnicke, MD (CD data analysis and patient management), M. Merschhemke, MD, MBA (MM; patient management) and H. B. Straub, MD (HBS; patient management) (all Epilepsy Center Berlin Brandenburg). Surgery was performed by T.-N. Lehmann (TNL), MD, and W. R. Lanksch, MD (WRL) (both Department of Neurosurgery, Charite-University Medicine, Berlin, Germany).

\section{Compliance with ethical guidelines}

Conflict of interest F.C. Schmitt and H.-J. Meencke declare that they have no competing interests.

For this article no studies with human participants or animals were performed by any of the authors. All studies performed were in accordance with the ethical standards indicated in each case.

Open Access. This article is licensed under a Creative Commons Attribution 4.0 International License, which permits use, sharing, adaptation, distribution and reproduction in any medium or format, as long as you give appropriate credit to the original author(s) and the source, provide a link to the Creative Commons licence, and indicate if changes were made. The images or other third party material in this article are included in the article's Creative Commons licence, unless indicated otherwise in a credit line to the material. If material is not included in the article's Creative Commons licence and your intended use is not permitted by statutory regulation or exceeds the permitted use, you will need to obtain permission directly from the copyright holder. To view a copy of this licence, visit http://creativecommons.org/licenses/by/4.0/. 


\section{References}

1. Asztely F, Ekstedt G, Rydenhag B, Malmgren K (2007) Long term follow-up of the first 70 operated adults in the Goteborg Epilepsy Surgery Series with respect to seizures, psychosocial outcome and use of antiepileptic drugs. J Neurol Neurosurg Psychiatry 78:605-609. https://doi.org/10.1136/ jnnp.2006.098244

2. Bien CG, Raabe AL, Schramm J et al (2013) Trends in presurgical evaluation and surgical treatment of epilepsy at one centre from 1988-2009. J Neurol Neurosurg Psychiatry 84:54-61. https://doi.org/ 10.1136/jnnp-2011-301763

3. Bower CM, Hays RD, Devinsky 0 et al (2009) Expectations prior to epilepsy surgery: an exploratory comparison of men and women. Seizure 18:228-231. https://doi.org/10.1016/j. seizure.2008.09.001

4. ChoiH,Sell RL, Lenert Letal (2008) Epilepsy surgery for pharmacoresistant temporal lobe epilepsy: a decision analysis. JAMA 300:2497-2505. https:// doi.org/10.1001/jama.2008.771

5. Dorfer, C, Czech, T\& Rössler, K (2019) Chirurgie der Temporallappenepilepsie. Z Epileptol. https://doi. org/10.1007/s10309-019-00297-5

6. Edelvik A, Rydenhag B, Olsson I et al (2013) Longterm outcomes of epilepsy surgery in Sweden. Neurology 81:1244-1251. https://doi.org/10. 1212/WNL.0b013e3182a6ca7b

7. Elwes RD, Dunn G, Binnie CD, Polkey CE (1991) Outcome following resective surgery for temporal lobe epilepsy: a prospective follow up study of 102 consecutive cases. J Neurol Neurosurg Psychiatry 54:949-952. https://doi.org/10.1136/jnnp.54.11. 949

8. Engel J Jr, McDermott MP, Wiebe S et al (2012) Early surgical therapy for drug-resistant temporal lobe epilepsy: a randomized trial. JAMA 307:922-930. https://doi.org/10.1001/jama.2012.220

9. Engel J Jr, Wiebe S, French J et al (2003) Practice parameter: temporal lobe and localized neocortical resections for epilepsy: report of the Quality Standards Subcommittee of the American Academy of Neurology, in association with the American Epilepsy Society and the American Association of Neurological Surgeons. Neurology 60:538-547

10. Engel J, Van Ness P, Rasmussen TB, Ojemann GA (1993) Outcome with respect to epileptic seizures. In: Surgical treatment of epilepsies, 2nd edn. Raven Press, New York, pp 609-621

11. Fisher RS, Acevedo C, Arzimanoglou A et al (2014) ILAE Official Report: a practical clinical definition of epilepsy. Epilepsia 55:475-482. https://doi.org/ 10.1111/epi.12550

12. Fisher RS, Cross JH, D'Souza C et al (2017) Instruction manual for the ILAE 2017 operational classification of seizure types. Epilepsia 58:531-542. https://doi.org/10.1111/epi.13671

13. Fisher RS, Cross JH, D'Souza C et al (2018) Anleitung ("instruction manual") zur Anwendung deroperationalen Klassifikation von Anfallsformen der ILAE 2017. Z Epileptol 31:282-295. https://doi. org/10.1007/s10309-018-0217-7

14. Fisher RS, Cross JH, French JA et al (2017) Operational classification of seizure types by the international league against epilepsy: position paper of the ILAE commission for classification and terminology. Epilepsia 58:522-530. https://doi. org/10.1111/epi.13670

15. Fisher RS, Cross JH, French JA et al (2018) Operationale Klassifikation der Anfallsformen durch die Internationale Liga gegen Epilepsie:
Positionspapier der ILAE-Klassifikations- und Terminologiekommission. ZEpileptol 31:272-281. https://doi.org/10.1007/s10309-018-0216-8

16. Gross RE, Stern MA, Willie JT et al (2018) Stereotactic laser amygdalohippocampotomy for mesial temporal lobe epilepsy. Ann Neurol 83:575-587. https://doi.org/10.1002/ana.25180

17. Hemb M, Palmini A, Paglioli E et al (2013) An 18year follow-up of seizure outcome after surgery for temporal lobe epilepsy and hippocampal sclerosis. JNeurol Neurosurg Psychiatry 84:800-805. https:// doi.org/10.1136/jnnp-2012-304038

18. Holtkamp M, Steinbrenner M (2016) Einstellungen zur (resektiven) Epilepsiechirurgie. Z Epileptol 30:93-97. https://doi.org/10.1007/s10309-0160091-0

19. Ilse A, Büntjen L, SchmittFC (2017) Stereotaktische Laserablation für fokale Epilepsien - Eine Literaturübersicht.ZEpileptol 30:152-161. https://doi. org/10.1007/s10309-017-0113-6

20. Janszky J, Janszky I, Schulz R et al (2005) Temporal lobe epilepsy with hippocampal sclerosis: predictors for long-term surgical outcome. Brain 128:395-404. https://doi.org/10.1093/brain/ awh358

21. Josephson CB, Dykeman J, Fiest KM et al (2013) Systematic review and meta-analysis of standard vs selective temporal lobe epilepsy surgery. Neurology 80:1669-1676. https://doi.org/10 1212/WNL.0b013e3182904f82

22. Kanchanatawan B, Limothai C, Srikijvilaikul T, Maes M (2014) Clinical predictors of 2-year outcome of resective epilepsy surgery in adults with refractory epilepsy: a cohort study. BMJ Open. https://doi.org/10.1136/bmjopen-2014-004852

23. Kelley K, Theodore WH (2005) Prognosis 30 years after temporal lobectomy. Neurology 64:1974-1976. https://doi.org/10.1212/01.WNL. 0000163998.01543.CF

24. Krucoff MO, Chan AY, Harward SC et al (2017) Rates and predictors of success and failure in repeat epilepsy surgery: a meta-analysis and systematic review. Epilepsia. https://doi.org/10.1111/epi. 13920

25. Landmark CJ, Patsalos PN (2010) Drug interactions involving the new second- and third-generation antiepileptic drugs. Expert Rev Neurother 10:119-140. https://doi.org/10.1586/ern.09.136

26. Mariani V, Revay M, D'Orio Pet al (2019) Prognostic factors of postoperative seizure outcome in patients with temporal lobe epilepsy and normal magnetic resonance imaging. J Neurol. https:// doi.org/10.1007/s00415-019-09394-x

27. McIntosh AM, Kalnins RM, Mitchell LA et al (2004) Temporal lobectomy: long-term seizure outcome, late recurrence and risks for seizure recurrence. Brain 127:2018-2030. https://doi.org/10.1093/ brain/awh221

28. McIntosh AM, Wilson SJ, Berkovic SF (2001) Seizure outcome after temporal lobectomy: current research practice and findings. Epilepsia 42:1288-1307

29. Ozanne A, Graneheim U, Ekstedt G, Malmgren K (2015) Patients' expectations and experiences of epilepsy surgery-a population-based long-term qualitativestudy. Epilepsia 57:605-611

30. Rosenow F, Bast T, Czech T et al (2014) Quality guidelines for presurgical epilepsy diagnosis and operative epilepsy therapy: 1st revised version. Nervenarzt 85:753-756. https://doi.org/10.1007/ s00115-014-4070-2

31. Rosenow F, Bast T, Czech T et al (2016) Revised version of quality guidelines for presurgical epilepsy evaluation and surgical epilepsy therapy issued by the Austrian, German, and Swiss working group on presurgical epilepsy diagnosis and operative epilepsy treatment. Epilepsia 57:1215-1220. https://doi.org/10.1111/epi. 13449

32. Schmidt D, Baumgartner C, Löscher W (2004) Seizure recurrence after planned discontinuation of antiepileptic drugs in seizure-free patients after epilepsy surgery: a review of current clinical experience. Epilepsia 45:179-186. https://doi.org/ 10.1111/j.0013-9580.2004.37803.x

33. Schmidt D, Stavem K (2009) Long-term seizure outcome of surgery versus no surgery for drugresistant partial epilepsy: a review of controlled studies. Epilepsia 50:1301-1309. https://doi.org/ 10.1111/j.1528-1167.2008.01997.x

34. Schwartz TH, Jeha L, Tanner A et al (2006) Late seizures in patients initially seizure free after epilepsy surgery. Epilepsia 47:567-573. https:// doi.org/10.1111/j.1528-1167.2006.00469.x

35. Stefan H, Schmitt FC (2017) Ablation und Epileptogenizität - Zur Beziehung von Läsion und Funktion. ZEpileptol 30:129-137. https://doi.org/ 10.1007/s10309-016-0097-7

36. Steinbrenner M, Kowski AB, Holtkamp M (2019) Referral to evaluation for epilepsy surgery: reluctance by epileptologists and patients. Epilepsia 60:211-219. https://doi.org/10.1111/ epi.14641

37. Taylor DC, McMackin D, Staunton $\mathrm{H}$ et al (2001) Patients' aims for epilepsy surgery: desires beyond seizure freedom. Epilepsia 42:629-633. https:// doi.org/10.1046/j.1528-1157.2001.34400.x

38. Téllez-Zenteno JF, Dhar R, Hernandez-Ronquillo L, Wiebe $S$ (2007) Long-term outcomes in epilepsy surgery: antiepileptic drugs, mortality, cognitive and psychosocial aspects. Brain 130:334-345. https://doi.org/10.1093/brain/awl316

39. Téllez-Zenteno JF, Dhar R, Wiebe S (2005) Longterm seizure outcomes following epilepsy surgery: a systematic review and meta-analysis. Brain 128:1188-1198. https://doi.org/10.1093/brain/ awh449

40. de Tisi J, Bell GS, Peacock JL et al (2011) The longterm outcome of adult epilepsy surgery, patterns of seizure remission, and relapse: a cohort study. Lancet 378:1388-1395. https://doi.org/10.1016/ S0140-6736(11)60890-8

41. West S, Nolan SJ, Cotton J et al (2015) Surgery for epilepsy. Cochrane Database Syst Rev. https://doi. org/10.1002/14651858.CD010541.pub2

42. Wiebe S, Blume WT, Girvin JP, Eliasziw M (2001) A randomized, controlled trial of surgery for temporal-lobe epilepsy. N Engl J Med 345:311-318. https://doi.org/10.1056/NEJM200108023450501

43. Wieser HG, Blume WT, Fish D et al (2001) Proposal for a new classification of outcome with respect to epileptic seizures following epilepsy surgery. Epilepsia 42:282-286. https://doi.org/10.1046/j. 1528-1157.2001.35100.x

44. Wu C, Jermakowicz WJ, Chakravorti S et al (2019) Effects of surgical targeting in laser interstitial thermal therapy for mesial temporal lobe epilepsy: a multicenter study of 234 patients. Epilepsia 60:1171-1183. https://doi.org/10.1111/epi.15565

45. Yoon HH, Kwon HL, Mattson RH et al (2003) Longterm seizure outcome inpatients initially seizurefree afterresective epilepsy surgery. Neurology 61(4):445-450

46. Zeng T, Li Y, An D et al (2014) Effectiveness of levetiracetam use following resective surgery in patients with refractory epilepsy: a prospective observational study. Epilepsy Res 108:1904-1911. https://doi.org/10.1016/j.eplepsyres.2014.09.034 
47. Bancaud J, Henriksen O, Rubio-Donnadieu F, Seino M, Dreifuss FE, Penry JK (1981) Proposal for revised clinical and electroencephalographic classification of epileptic seizures. From the Commission on Classification and Terminology of the International League Against Epilepsy. Epilepsia 22:489-501. https://doi.org/10.1111/j. 1528-1157.1981.tb06159.x

Hier steht eine Anzeige.

\section{算 Springer}

